\title{
XLIX.
}

\section{Ueber ein Verfahren in der Daguerrotypie, die hellen und dunklen Partien gleich deut- lich darzustellen.}

\author{
Von \\ Belfteld-Leféore und Léon Foucault.
}

(Ann. de Chim. et de Phys. 3. Ser. T. XIX. p. 125.)

Wenn man eine viel grōssere Menge Brom bei der Präparatur der jodirten Platten anwendet, als dieses gewöhnlich der Fall ist, so werden dieselben zwar weniger emp indlich, erhalten aber die Eigenschaft, die helleren sowohl als die dunkleren Töne gleich gut aufzunehmen. Das Verfahren, welches die Verf. zu diesem Zwecke empfehlen, gelingt sehr leicht in geübten Hānden. Man jodirt die polirte Platte zuerst wie geworhnlich und lässt nun auf irgend eine Weise wenigstens drei Mal so viel Brom von solchen Platten absorbiren, als man gewoohnlich, um dic empfindlichsten Platten zu erzengen, anzuwenden pllegt. Wührend man gewőhnlich nur so viel Brom auf die Platte treten lăsst, dass die Farbe der Platte nicht verăndert wird, so lässt man lüı diese Art Platten so viel davon absorbiren, dass sie bläulich-violett anlaufen.

Die Empfindlichkeit solcher mit Brom überladenen Platten sinkt bis auf ein Drittel, dieselben sind aber dafür geeignet, vollkommene Bilder von Gegenständen zu geben, welche die verschiedensten Töne haben. Es wurden auf solchen Platlen Bilder erhalten, welche die Wolken an Himmel, den Baumschlag und weisse Häuser fast so vollkominen darstellten, als wenn ein Künstler sie gezeichnet hätte. 